\title{
A CONSUMER TENDENCY SURVEY ON RURAL TOURISM IN ANKARA, TURKEY
}

\author{
C.Serefoglu ${ }^{37}$ \\ E.Gökkaya ${ }^{38}$ \\ A.Demir ${ }^{39}$
}

\begin{abstract}
With its underground resources, rich flora and natural beauties Ankara has one of Turkey's most outstanding rural areas. Yet, these beauties are recognized neither by natives nor by foreigners. The main aim of this research is to determine the factors which affect the choice of the population who lives in Ankara city center to visit rural areas as well as general preferences of visitors. Ankara city center population is assumed approximately 5 million and with $99 \%$ confidence interval and 5\% error margin the sample size is found as 661. Before the application of surveys in the field, surveys are shared with 10 people and proper adjustments made according to the feedbacks received. Face-to-face interviews with 661 people are applied. During the data evaluation process, surveys which contain missing and inconsistent data are excluded from the sample size. Missing and inconsistent surveys which was $7 \%$ of total are removed and ultimately with 616 surveys analyses continued. Probit model is preferred due to the small sample size. The model in which independent variables affecting decisions of people who visit rural Ankara biweekly are investigated, whereas people who prefer guide and have a connection with current rural settlement have a positive effect and birthplace has a negative effect.In consequence of the survey research it came out that citizen's awareness level about rural and tourism destinations in Ankara is low. To increase awareness it is needed that institutions and organizations conduct collaborative work for rural area. As continuation of the research, people living in the country side and their expectation from tourism are going to determine more reliable deductions.
\end{abstract}

Key words: Rural tourism, rural areas, rural visitors, shopping malls, Ankara

\section{INTRODUCTION}

Tourism sector play a vital role for the economic development of the countries. New searches in tourism, shifting attitudes of visitors' expectations, increasing interest for discovering local culture and new places as well as reaction to mass tourism have increased considerably the role of alternative tourism activities. Of tourism alternatives, rural tourism, as an economic instrument in the rural development, become even more important in the last decades. According to the World Bank data, international tourism income increased to $\$ 1.437$ trillion from $\$ 486,753$ billion in 1995 . For those years, international tourism income for Turkey reached to $\$ 35,413$ billion. The number of the

\footnotetext{
${ }^{37}$ Head of Department of Business Development and Stratgy Unit, Ankara Development Agency, Asagi Ovecler Mah, 1322. Cadde, No:11, Cankaya, Ankara-Turkey, cserefoglu@gmail.com

${ }^{38}$ Expert at Ankara Development Agency
} 
international tourists in Turkey reached to 39,4 million in 2015. Those figures clearly show that how tourism is important for Turkish economy even though rural tourism and other alternatives tourism break downs have not developed yet.

Tourism has been found to be linked to food and beverage service companies by $37.4 \%$ in urban areas and $40.1 \%$ in rural areas. Similarly, it was found that tourism activities contributed to real estate activities by $13.7 \%$ in urban areas and by $13.6 \%$ in rural areas according to the Statistical feature report issued in 2011. In other words rural tourism should be perceived as a mean of sustainability which creates new jobs which is one of the most crucial needs by declining rural area or by reviving traditional customs. Rural tourism including eco-tourism, farm-based tourism, agro-tourism, nature tourism and village tourism has a big potential for tourists/visitors seeking adventure and locals living in rural and have a bond with tourism activities. Tourism infrastructure in rural areas are vital importance. More developed infrastructure acquires more tourism revenues. For example, France, Austria and Greece represent 23.4\%, 9.3\% and $6.8 \%$ of the "rural" bed places in the EU-27 and only $21 \%, 3.4 \%$ and $3 \%$ of the total EU-27 bed places, respectively (EC, 2012). As the tourism revenues increase, growth simultaneously triggered in rural areas.

Rural areas in Turkey, particularly in Ankara, cannot benefit from economic growth as expected. The main problem of this research is why rural areas are not preferred by the urban residents and to find the main preferences and tendencies of the rural visitors. This study thus aims to identify perceptions and tendencies of urban people about rural tourism. Not only is Ankara a place where per capita income is one of the highest in Turkey, but the share of high technology in industry is also high. However, rural Ankara, with its natural resources and scenic beauty, is one of the outstanding places in Turkey. But, this beauty is not discovered both by international visitors and national visitors. Of the districts, only a few districts have been successful to promote what they have.

During the improvement of rural tourism, one of the most important issues is to pay attention to selection of tourism volunteers and employees. On one side they reflect the rural culture in villages and towns and on the other side they will improve the technological infrastructure that will enable rural tourism to attract foreign tourists. To achieve that approach, establishment of more tourism cooperatives and improvement of their institutional capacity is extremely needed.

The proximity to the domestic and international transportation networks again constitute an important potential for Ankara's tourism. The extravert approach of the village people and the adoption of tourism may differ from north and south of Ankara to east and west. There is thus a need for a number of awareness activities and extension trainings for the public to embrace tourism, especially in areas that are lagging behind of development in terms of socio-economic indicators. It will also be important to consider tourism as an economic tool and to develop in this direction. Within the scope of village tourism, lack of enough accommodation facilities and 
inadequate infrastructures; within the scope of nature tourism lack of cycling and walking routes, use of natural jeopark areas unconsciously, and lack of tourism-village tourism-oriented strategy and concept tour programs are the issues that are needed to improve mostly (Ankara Development Agency, 2017).

The statistics show that the nightly accommodation in rural Ankara is too low due to a number of factors such as lack of infrastructure, lack of product diversity, promotional activities etc. in contrast to studies showing that growing numbers of city settlers get away from urban areas to rural areas (Telfer, 2002). Therefore, some local strategies aiming to attract city dwellers need to be implemented in the poorer regions. Those districts need to be connected with urban centers surrounding them regarding physical infrastructure, common events, training activities of local people. With respect to urban consumers, promotional activities need to be organized in consultation with related institutions. The research also shows that the rural values and historical places are not known by urban people. Awareness raising activities are quite important. Even though there is a historical tourism corridor called "Silk Road" in Ankara, all the districts taken in this route are lack of integrated management. So, the management of that corridor through local municipalities is insufficient for the whole corridor. The developing institutional capacity of the related NGO's and municipalities plays a vital role for the development of this route. Although some vocational schools in the last decades have launched some tourism programs, the number of local guides is still insufficient to meet the demand and to promote the region.

Rural tourism contributes greatly to socio-economic rural development by employing the female population living in rural areas, revitalizing local economies as well as preventing out-migration. In addition, it prevents rural cultures from disappearing, supports the conservation of natural environments, easily integrates with other types of tourism, allows tourism to be done for twelve months, and does not lead to mass tourism by targeting small groups. When all these benefits of rural tourism are taken into account, it is understood that Turkey should be applying the similar policies in a planned and controlled manner.

When analyzed the instruments and measures which can encourage rural visits in Ankara, more affordable prices regarding accommodation, transportation as well as diversified rural activities, more effective promotional activities and advertising and more attractive rural tourism regions with a good physical infrastructure are the main expectations. Additionally, actively using e-trade and e-commerce for local products as well as promoting accommodation facilities through internet and becoming member for international tourism organizations are becoming more and more popular and gross value added for the local economies.

Rural visitors prefer to have different experience on activities, lifestyles and traditions of communities. This inclusion in daily life of rural people provides travelers a unique experience. Rural tourism means more small travel agencies and more niche products. It also means smaller communities; smaller accommodation objects, smaller groups or 
individuals' travels will gain more and more popularity in future. Bessière (1998) states that "rural areas are now increasingly seen as places for entertainment, leisure activities, and second homes and as an alternative to urban residential areas". In a similar stance underlined by Tyran (2008) that expectations and tendencies rural tourism fits perfectly to all those needs. Telfer (2002) concurs with this view that rural areas are becoming increasingly popular for urban residents since they need to get rid of the hectic life of urban areas.

As provided by the researches that tourism sector has a strong linkages with other sectors. Giannakis (2014) found that the output of the other sectors increases by 0.43 million euro if the output of tourism sector increases by 1 million euro. Another research conducted by Tatar\&Köroğlu (2017) in Beypazari, Ankara reveals that female labor force working in tourism sector triggered an increase of female employment increased the entrepreneurship and the number of female that shifted from being housewife to entrepreneur isn't low. Traditional eating and drinking activities that develop with rural tourism, pensions, and handcrafts are the main areas in which women in rural can create jobs for themselves. The study shows that when the sex ratios of the entrepreneurs are examined, it is seen that the rate of female entrepreneurs is much higher than in many places in Turkey. This has had positive effects on social life balances in rural areas. According to study almost half of the entrepreneurs in Beypazar1 with $46.8 \%$ are females. It shows that there are new areas of employment and employment opportunities are created for women who have no alternative than to contribute to family affairs in the countryside. In other words, proposition of "rural tourism development is causing an increase in the rate of female employment" has been confirmed by survey results.

Same study indicates that majority of people think that rural tourism will contribute positively to the economic development of the region, increase the incomes, the standard of living and provide new jobs for local people. In addition to that expectations entrepreneurs, in all sectors think that the potentials of Beypazarı district are not used with high rates. Study revealed that if lack of promotion and advertising; lack of qualified staff and infrastructural problems such as parking and transportation are solved tourism activities would flourish apace. In other words the rural tourism potentials located around Beypazarı are not used as much as the potentials in urban by entrepreneurs and local people.

Supporting farmers' cooperatives which are non-functional and turn them into functional tourism co-operatives will provide important contributions to protect the vitality of rural areas and raise rural tourism activities. As emphasized by Soykan (2001), instead of adopting normative approaches in creating exemplary co-operative structures, it is necessary to adopt approaches that priority is given to entrepreneurship and creativity that takes place in the whole process of education, which arises from regional necessity. Again Soykan (2001) summarizes formula of success achieved by Şirince Village in 3 facts which are historical and cultural heritage, geographical 
location and natural attractions, extravert attitude of the people and their motivation on tourism.

Based on this information, it is assumed that there are a number of efforts can be done to increase tourism incomes in Turkey. For istance, Luxton (2015) highlighted that there is a need to create services and products that will appeal to consumption habits of countries such as China, US, Germany, and UK which spend most on tourism activities. In addition to package tours targeting mass tourism, there is a need to develop rural tourism, which serves smaller and niche groups targeting rural areas. Traveling with more relaxed and smaller groups has becomes trend in 2010's. With increasing income and mobility, tourists tend to plan their own vacations through web-based software that guarantees the best price and quality service. Internet and applications pops up in every point, from room reservation to the event that will be participated; from food that will be ordered to taxi service. Thus it may be beneficial for countries to organize their tourism practices and measures in such a way as to conform to these trends.

\section{MATERIALS AND METHODS}

\section{General Framework of the Survey and Methodology}

\section{DETERMINING SAMPLE SIZE}

Ankara city center population is assumed approximately 5.000.000 and with \% 99 confidence levels and \%5 margins of error the sample size is found as 661 . Before the surveys are applied in the field they are shared with 10 people and the feedbacks are received. As the result of the feedback questions which cannot be understood and questions which are thought unnecessary are removed and questions which are thought to have missing expressions when they are read are corrected. Surveys are conducted by team of experts including 8 people in January-February months with the way of face to face surveys. While the surveys are conducted it is benefitted from common areas such as shopping malls where urbanites go in peak hours. Although normal sample size is found as 661 as the result of the equation, face to face surveys are applied to total 777 people. In the process of the evaluation of survey's data questionnaires involving missing or inconsistent data are not included. Surveys indicating missing and inconsistency [which equals to approximately $15 \%$ of the total applied survey in number are removed] and in the end with 616 surveys continued to analysis.

\section{ANKARA REGION}

Ankara region is located in central part of Turkey with 24.521 square $\mathrm{km}$. In total there are 25 districts, 16 of them are in the periphery while 9 districts are located in the centre. Serefoglu and Yalcin (2015) indicated that population density in rural Ankara is quite low, the main economy in the periphery districts are mainly based on the 
agriculture and tourism. The basic features of rural areas are aging population, low fertility rate, negative net migration as much as lack of infrastructure regarding health, education and public finance while the region has one of the highest GDP shares in Turkey. The rate of advanced technologies in the industry is much higher than other regions. The rural part of Ankara is not preferred by urban residents.

\section{REGRESSION ANALYSIS}

Probit and logit models take place in literature as non-linear functions of unknown coefficients which are used commonly in optional models consisting of two option answer. Amemiya (1981) states that sample sizes which have heavier tailed are more suitable for logit models. Likewise, Amemiya also indicates that Çakmakyapan and Göktaş (2013) logit models are more suitable to sample sizes like 500 and 1000 and smaller sample sizes can be preferred for probit models. Probit model is used in analysis because the sample size is less than 500 for the determined dependent factors.

\section{Probit Model}

Wooldridge (2006) probit model is $\mathrm{Zn}=\mathrm{Xn} \beta+\mathrm{u}$. Whereas $\beta$ is a vector of parameters which is the junction point of covariate variables; $x n$ is a vector of covariates; $u$ is the error term either in standard logistic distribution or in standard normal distribution. In either case $\mathrm{u}$ shows symmetrical distribution about zero. Zn represents unobservable factors which affect decisions of people who prefer guide.

RT represents observed dichotomous variable which shows whether individuals prefer a guide or not.

It is formulized as the following;

$\mathrm{RTn}=0$ if $\mathrm{RTn} * \triangleleft) ;(2)$

$\mathrm{RTn}=1$ if RTn* 0 (3)

Dual answers which have two options like Yes/No explain the effects to answer which follows probability of $x$.

$\mathrm{P}(\mathrm{RT}=1 \mid \mathrm{x})=\mathrm{P}\left(\mathrm{RTn}^{*}>0 \mid \mathrm{x}\right)=\mathrm{P}[\mathrm{e}>-(\beta 0+\mathrm{x} \beta \mid \mathrm{x}]=1-\mathrm{G}[-(\beta 0+\mathrm{x} \beta 0]=\mathrm{G}(\beta 0+\mathrm{x} \beta)$

$\mathrm{Xj}$ 's effect direction over $\mathrm{E}(\mathrm{RT} * \mid \mathrm{x})=\beta 0+\mathrm{x} \beta$ and (5)

Over $\mathrm{E}(\mathrm{RT} \mid \mathrm{x})=\mathrm{P}(\mathrm{y}=1 \mid \mathrm{x})=\mathrm{G}(\beta 0+\mathrm{x} \beta)$ is the way that similar with one another

As stated by Wooldridge (2006) The Smallest Square method is not possible because of $\mathrm{E}(\mathrm{y} \mid \mathrm{x})$ 's non-linear nature. That is why maximum likelihood methods have to be used for calculating limited dependent variable models. Maximum likelihood can be written as the following;

$f(\mathrm{RT} \mid \mathrm{xi} ; \beta)=[\mathrm{G}(\mathrm{xi} \beta)] \mathrm{y}[1-\mathrm{G}(\mathrm{xi} \beta)] 1-\mathrm{y}, \mathrm{RT}-0.1$ (7)

It ends up with $y=1, G(x, \beta)$ and the time $y=0$, we get $1-G(x i \beta)$. Observed function of $\log$ likelihood is a function of parameters and (xi, yi) data is found as the following. $\operatorname{li}(\beta)=$ RTilog $[\mathrm{G}(\mathrm{xi} \beta)]+(1-\mathrm{RTi}) \log [1-\mathrm{G}(\mathrm{xi} \beta)]$. (8) 
In the light of formula stated above independent variables which affects decisions of people who visit rural areas at least once every two week and people who visit shopping malls at least once every two week are calculated.

\section{FINDINGS}

As indicated in Table 1, $53.4 \%$ (329) of the 616 respondents that were considered in the study are males, and $46.6 \%$ (287) are females. The educational attainment of the respondents is in favour of higher level of education, $48.92 \%$ (295) acquired a university degree followed by $11.77 \%$ (77) of post graduate degree. When comparing the above figures with the data elaborated on the basis of TURKSTAT data shown in Table 2, our sample has higher income and education levels while female rate and median age are quite similar with Ankara's average. Regarding working status, the share of respondents employed in private and public sector are $33 \%$ and $31.7 \%$, respectively. $18.2 \%$ of the respondents including students indicated themselves as unemployed. Taking into account income level of respondents, it was found that the middle income group was significantly predominant with $78 \%$ while $17 \%$ of the respondents come from higher income group. Interestingly, more than $60 \%$ of the respondents living in Ankara have roots with countryside and farming. With respect to marital status of the respondents, $63 \%$ of those is married and $57 \%$ have children.

Table 1. Characteristic of the Sample

\begin{tabular}{|l|l|l|}
\hline Sample Size:616 & Freq. & \% \\
\hline Gender & 616 & 100 \\
\hline Male & 329 & 53.4 \\
\hline Female & 287 & 46.6 \\
\hline Age & 616 & Median: 35.6 \\
\hline Employment Status & 615 & 100 \\
\hline Public sector & 195 & 31.7 \\
\hline Private sector & 203 & 33 \\
\hline Unemployed & 112 & 18.2 \\
\hline Student & 32 & 5.2 \\
\hline NGO's & 73 & 11.9 \\
\hline Marital status & 616 & 100 \\
\hline Married & 389 & 63.15 \\
\hline Single & 227 & 36.85 \\
\hline Having children Status & 607 & 100 \\
\hline Yes & 348 & 57.33 \\
\hline No & 259 & 42.67 \\
\hline Education & 603 & 100 \\
\hline Pri\&High School & 237 & 39.30 \\
\hline
\end{tabular}




\begin{tabular}{|l|l|l|}
\hline Graduate & 295 & 48.92 \\
\hline Post Graduate & 71 & 11.77 \\
\hline Monthly Income (1 TL=f0,24) & 612 & 100 \\
\hline$\leq, 350$ TL & 26 & 4.25 \\
\hline 1,351 TL-2,500 TL & 153 & 25.00 \\
\hline 2,501 TL-4000 TL & 197 & 32.19 \\
\hline 4001 TL-6000 TL & 127 & 20.75 \\
\hline$>6000$ TL & 109 & 17.81 \\
\hline Any roots in the country or farming & 616 & 100 \\
\hline Yes & 384 & 62.3 \\
\hline No & 232 & 37.7 \\
\hline
\end{tabular}

Table 2. Comparison of Sample Socio-demographics Versus Ankara's Population.

\begin{tabular}{|l|l|l|}
\hline Socio-demographics & Sample & Ankara's Population* \\
\hline Female (\%) & 46.60 & 50.37 \\
\hline Graduates (\%) & 61 & 25.54 \\
\hline Median Income (TL) & 3,290 & 1,703 \\
\hline Median age & 35.6 & 32.3 \\
\hline
\end{tabular}

*Elaborated from data extracted from TURKSTAT

$71 \%$ of the respondents indicated that they were born in city centre while $29 \%$ of those were born in rural areas and migrated to urban areas. So, it can be said that the interviews were made with people who experienced the urban life from early childhood. It is thus expected that the majority of the respondents have knowledge about rural areas of Ankara.

According to the TURKSTAT data, $59 \%$ of the expenditures per capita have been made by domestic visitors while $41 \%$ was made by international visitors. This rate needs to be increased regarding foreign currency returning. In general terms, the most challenging issue for rural areas is lack of product diversification in tourism. Besides, there are some significant problems regarding introducing natural beauty of the region. Therefore, the rural districts are either planned as product oriented or as tourism corridors.

This study aims to identify perceptions and tendencies of urban people about rural tourism. Not only is Ankara a place where per capita income is one of the highest in Turkey, but the share of high technology in industry is high. However, rural Ankara, with its natural resources and scenic beauty, is one of the outstanding places in Turkey. Hardly, this beauty is discovered neither by international visitors nor national. Of the districts, only a few districts have been successful to introduce what they have. With this study, the similarities and differences between visitors of shopping malls and rural areas have been identified and focused on why rural areas are not preferred by the visitors. 
The interviews were collected and evaluated with 616 persons living in urban areas. 60 $\%$ of the respondents have at least a bachelor degree. The rate of workers and officials are $27 \%$ and $24 \%$, respectively. With respect to monthly salary, only $18 \%$ comes from higher income groups while a significant number of respondents $(61 \%)$ indicate that they come from middle income groups. Also, the rate of private car ownership, which is very important to make travelling easier from urban to rural area, is $59 \%$. Only $81 \%$ of those prefer to visit rural Ankara with their cars while $19 \%$ prefer to travel with local bus services. More than $75 \%$ of the respondents indicated that they were born in urban areas. Supporting this figure, more than $70 \%$ of those indicated that they spend the first 12 years in their life in urban areas while $29 \%$ of those spend in rural areas. With respect to having rural roots, $62 \%$ of the respondents indicated that they have no roots or connection with rural areas while the rest of those $(38 \%)$ have rural connection and roots. Regarding travel preferences, $43 \%$ of the respondents prefer to travel to rural districts of Ankara in a way of daily visits (57\%). The rate of visitors preferring to accommodate in the places where they go is only $10 \% .37$ of $\%$ of those prefer to stay in the hotel while the rest prefers to stay in their family house or friends' house. Taking into consideration of average spending per travel, a question was asked how much money is spent per travel. $87 \%$ of the respondents overwhelmingly indicated that they spend less than TRY 300 for their own travel and accommodation while $10 \%$ spends between TRY 300-500. Only $1 \%$ indicated that they spend above TRY 700. With respect to benefiting from a tourist guide, only $10 \%$ indicated that they would need a tourist guide for their travels. When asked to respondents whether or not they have an idea about Ankara's districts, more than $80 \%$ indicated yes I know, but when asked specific places, more than $60 \%$ of those indicated that they do not know that place. Most of the respondents indicated that they don't visit a lot of rural districts of Ankara. When a question was asked why people do not want to visit rural districts, lack of infrastructure, distance from city centre, lack of financial support of local institutions and insufficient number of local guides in the districts come into prominence as main reasons.

When analyzed the instruments and measures which can encourage rural visits in Ankara, more affordable prices regarding accommodation, transportation as well as diversified rural activities, more effective promotional activities and advertising and more attractive rural tourism regions with a good physical infrastructure are the main expectations. 
Table 2. Variables and Definitions

\section{Dependent variable: Rural visits}

\begin{tabular}{|c|c|}
\hline Variable & Definition \\
\hline $\begin{array}{l}\text { Rural holiday } \\
\text { frequency }\end{array}$ & $\begin{array}{l}\text { Rural areas are visited at least one time in every two weeks. } \\
(1=\text { yes; } 0=\text { no) }\end{array}$ \\
\hline Guide preference & Preference for guide $(1=$ yes; $0=$ no $)$ \\
\hline Birth of place & $1=$ village $; 2=$ town $; 3=$ city \\
\hline Marital status & $1=\operatorname{man} ; 0=$ woman \\
\hline Daily travel length & $1=<1$ hour; $2=1-2$ hours; $3=3$ hours; $4=$ more than 4 hours \\
\hline $\begin{array}{l}\text { Having rural } \\
\text { roots\&connections }\end{array}$ & $1=$ yes $; 0=$ no \\
\hline $\begin{array}{l}\text { With whom the } \\
\text { visitors usually } \\
\text { visits rural Ankara }\end{array}$ & $\begin{array}{l}1=\text { my own; } 2=\text { with friends; } 3=\text { with wife } ; 4=\text { wife and } \\
\text { children; } 5=\text { with children; } 6=\text { with group of people; } 7=\text { other }\end{array}$ \\
\hline
\end{tabular}

In the model, which analyses the independent variables that are effective in decision making for visiting rural Ankara (dependent variable) at least once in two weeks, people preferring to use guide services and those having rural roots or connections were found to have positive impact on the probability to visit rural areas at least once in two weeks while birth of place was found to have a negative impact. In explaining with economic terms, those preferring guide in their visits increases the probability to visit rural areas by $6 \%$. Similarly, those having rural roots or connections increase the probability to visit rural areas. In this regard, the basic features of people visiting rural areas need to be analyzed. Lastly, people who were born in rural areas prefer to visit rural areas more than those which were born in urban areas.

Table 3. Promit Model Number of Observation:183; LR chi2 (6)=20.63; Prob $>$ chi2 $=0.0021 ;$ Log likelihood $=52.825293$;

Pseudo $\mathrm{R}^{2}=0.1634$ Dependent variable: Frequency for rural Ankara

\begin{tabular}{|l|r|r|r|r|}
\hline Variable & Coefficient & $\begin{array}{l}\text { Standar } \\
\text { error }\end{array}$ & $\begin{array}{l}\text { Marginal } \\
\text { effect }\end{array}$ & Standar error \\
\hline Constant & 0.002353 & 0.6476485 & - & \multicolumn{1}{|c|}{} \\
\hline Guide preference & $0.411301^{*}$ & 0.2341401 & $0.0589914^{*}$ & 0.0341 \\
\hline Birth of place & $-0.26891^{*}$ & 0.1572973 & $-0.0385687 *$ & 0.02233 \\
\hline Marital status & -0.33908 & 0.2829955 & -0.0524659 & 0.04653 \\
\hline Daily travel length & -0.20847 & 0.1443693 & -0.0298997 & 0.0205 \\
\hline $\begin{array}{l}\text { Having rural } \\
\text { roots\&connections }\end{array}$ & $1.066651^{*} *$ & 0.2889731 & $0.2149784 *$ & \\
\hline $\begin{array}{l}\text { With whom the } \\
\text { visitors usually visits } \\
\text { rural Ankara }\end{array}$ & -0.1171 & 0.0880699 & -0.0167945 & 0.0694 \\
\hline
\end{tabular}

$* * *=$ indicates significance at $1 \%$ level; $* *=$ at $5 \%$ level; $*=$ at $10 \%$ level 


\section{CONCLUSIONS}

Rural tourism makes great contribution to socio-economic development of rural areas with employment, particularly for the female population living in rural areas, revitalizing local economies as well as preventing out-migration. In addition, it prevents rural cultures from disappearing, supports the conservation of natural environments, easily integrates with other types of tourism, allows tourism to be done for whole year, and does not lead to mass tourism because its target is mostly small groups. When all these benefits of rural tourism are taken into account, it is understood that Ankara should be applying the similar policies in a planned and controlled manner.

Promit model shows that people preferring to use guide services and those having rural roots or connections were found to have positive impact on the probability to visit rural areas at least once in two weeks while birth of place was found to have a negative impact. In explaining with economic terms, those preferring guide in their visits increases the probability to visit rural areas by $6 \%$. Similarly, those having rural roots or connections increase the probability to visit rural areas by $21 \%$.

In conclusion, it comes out that the awareness level about rural Ankara among urban population is found quite low. Therefore, a strong collaboration among relevant institutions is needed. Regarding rural tourism, the human capital in the rural districts is insufficient to carry out the required promotional activities. So, creating or developing the existing local capacity through universities or relevant institutions is extremely important for developing rural tourism. This study only takes into account the perspective. In the following study rural perspective should be included for allowing necessary comparison between urban and rural.

\section{REFERENCES}

1. Amemiya, T. (1981). Qualitative Response Models: A Survey. Journal of Economic Literature, 19:1483.

2. Bessière, J. (1998). Local Development and Heritage: Traditional Food and Cuisine as Tourist Attractions in Rural Areas. Sociologia Ruralis, Vol.38, No. 1, page. 21.

3. Cakmakyapan, S. and Goktas, A. (2013). A COMPAR SON OF Binary Logit and Probit Models with a Simulation Study. The Journal of Social and Economic Statistics, Vol. 2 (1), Summer 2013.

4. EC (2012). Rural Development in the EU Statistical and Economic Information Report 2012 . European Commission Directorate-General for Agriculture and Rural Development, p. 263.

5. Giannakis, E. (2014). The role of rural tourism on the development of rural areas: the case of Cyprus. Romanian Journal Of Regional Science, Vol. 8, No.1, Summer 2014. 
6. Luxton, E. (2015). “Which Country's Tourists Spend the Most Money?” World Economic Forum, World Economic Forum, 30 Dec. 2015, www.weforum.org/agenda/2015/12/which-countrys-tourists-spend-the-mostmoney/.

7. Okech, R., Haghiri, M. and George, B.P. (2012). Rural tourism as a sustainable development alternative: an analysis with special reference to Luanda, Kenya. Sustainability, Tourism\&Environment In the Shift of a Millennium: A peripheral view.

8. Statistical Feature Report. (2011). - Monitoring Engagement with the Natural Environment (MENE) survey, Year 1 - March 2009 to February 2010, Year 2 March 2010 to February 2011.

9. Soykan, F. (2001). “Ege Bölgesinden kırsal turizme özgün bir örnek: Şirince Köyü(Selçuk/zmir). Maltepe Üniversitesi Meslek Yüksekokulu Dergisi (2001/1).

10. Telfer, D.J. (2002): Tourism and Regional Development. In: R. Sharpley \& D.J. Telfer (eds.):

11. Tyran, E .(2007). Trends In World Tourism As A Chance Of Rural Tourism Development.Inproforum2007, ocs.ef.jcu.cz/index.php/inproforum/INP2007/paper/viewFile/495/423.

12. Tourism and Development: Concepts and Issues. Channel View Publications.

13. Wooldridge, J. (2006). Introductory of Economics, 4th Edition. South Western.

14. WTO. (2004). Rural Tourism in Europe: Experiences, Development and Perspectives. Madrid. 